\title{
ANALISIS IDENTITAS BUDAYA LOKAL PADA FILM TOBA DREAMS SUTRADARA BENNI SETIAWAN MELALUI MISE EN SCENE DAN DIALOG
}

\author{
Dani Manesah \\ Program studi televisi dan film \\ Universitas Potensi Utama \\ manesahh@gmail.com
}

\begin{abstract}
ABSTRAK
Penelitian yang berjudul Analisis Identitas Budaya Lokal Pada Film Toba Dreams Sutradara Benni Setiawan Melalui Mise en scenedan Dialog.Penelitian inibertujuan untuk menganalisis identitas budaya Batak Toba dan memaparkan wujud budaya tersebut melalui mise-en-scene dan dialog yang terdapat pada film Toba Dreams Sutradara Benni Setiawan.Identitas budaya lokal tersebut dapat dilihat melalui wujud - wujud budaya. Wujud budaya Batak Toba tersebut dapat dilihat melalui aspek mise-en-scene (setting, kostum dan make up, pergerakan pemain) dan dialog.Metode penelitian yang digunakan dalam penelitian ini menggunakan deskriptif kualitatif, dimana objek dalam penelitian ini adalah film Toba Dreams Sutradara Benni Setiawan.Adapun hasil dalam penelitian ini adalah bahwa identitas budaya Batak Toba dapat dilihat dari wujud budaya yang terdapat pada film Toba Dreams Sutradara Benni Setiawan seperti aspek mise-en-scene dan dialog seperti setting ruang dan waktu cerita, kostum dan make up yang digunakan oleh pemain, pergerakan akting dan karakter pemian, serta dialog yang diucapkan oleh para pemain.
\end{abstract}

Kata Kunci : Film, Identitas Budaya Lokal, Toba Dreams

\begin{abstract}
Research entitled Analysis of Local Cultural Identity in Benni Setiawan's Toba Dreams Films Through Mise en scenedan Dialog. This research aims to analyze the cultural identity of the Toba Batak culture and expose these cultural forms through mise-en-scenes and dialogue contained in the Toba Dreams film director Benni Setiawan. The local cultural identity can be seen through cultural forms. The Toba Batak culture can be seen through the aspects of mise-en-scene (settings, costumes and make-up, player movements) and dialogue. The research method used in this study uses descriptive qualitative, where the object in this study is the film Toba Dreams Director Benni Setiawan. As for the results in this study is that the cultural identity of the Toba Batak culture can be seen from the cultural form contained in the film Toba Dreams Director Benni Setiawan such as aspects of mise-en-scene and dialogue such as the space and time settings of the story, costumes and makeup used by players, acting movements and characters, and dialogues spoken by the players.
\end{abstract}

Keywords: Film, Local Cultural Identity, Toba Dreams 


\section{PENDAHULUAN}

Budaya atau kebudayaan berasal dari bahasa sansekerta yaitu buddhayah, yang merupakan bentuk jamak dari buddhi (budi atau akal) diartikan sebagai hal- hal yang berkaitan dengan budi dan akal manusia, dalam bahasa inggris kebudayaan disebut culture yang berasal dari kata latin colere yaitu mengolah atau mengerjakan dapat diartikan juga sebagai mengolah tanah atau bertani, kata culture juga kadang sering diterjemahkan sebagai "Kultur" dalam bahasa Indonesia. Sedangkan menurut Kuntjaraningrat bahwa "kebudayaan" berasal dari kata sansekerta buddhayah bentuk jamak dari buddhi yang berarti budi atau akal, sehingga menurutnya kebudayaan dapat diartikan sebagai hal- hal yang bersangkutan dengan budi dan akal, ada juga yang berpendapat sebagai suatu perkembangan dari majemuk budi- daya yang artinya daya dari budi atau kekuatan dari akal (Koentjaraningrat, 1993: 9).

Kebudayann yang pada awalnya belum diketahui masyarakat luas, kini bisa disaksikan oleh masyarakat melalui sebuah layarkaca dan melalui film. Film sebagai sebuah karya seni yang didukung dengan menggunakan sebuah unsur gambar dan unsur suara dalam menyampaikan sebuah pesan kepada penontonya.dalam meningkatkan sebuah kesadaran terhadap penonton yaitu dengan menyempurnakan permainan dan upaya senyata dan sehalus mungkin, seperti seni akting yang lebih nyata, pembenahan struktur cerita, pembenahan setting budaya yang lebih dapat dipertanggungjawabkan, serta penyuguhan gambar yang lebih indah. Salah satu hal yang berkontribusi dalam penciptaan karya film tersebut adalah kebudayaan itu sendiri. Wujud kebudayaan tersebut dapat kita lihat melalui sebuah mise en scene didalam film seperti setting, kostum dan make up, pergerakan pemainserta dialog dalam sebuah film. Dengan bentuk penayangannya banyak film yang diproduksi untuk dilihat dan didengar oleh banyak masyarakat umum, karena film merupakan salah satu media yang dapat digunakan sebagai sarana hiburan yang dapat dijadikan media refleksi pikiran dan dapat juga digunakan untuk mendidik, banyak nilai yang dapat diambil dari tayangan tersebut.Wajah perfilman Indonesia saat ini seakan-akan hanya mengikuti trend dan komersil. Sebagai contoh peluncuran film dengan tema horor membuat sineas terkesan hanya mengejar nilai jual dari pada memperhatikan tema dalam film tersebut yang dapat mendidik.Tujuan perfilman antara lain terwujudnya kecerdasan kehidupan bangsa, terpeliharanya persatuan dan kesatuan bangsa, dikenalnya budaya bangsa oleh dunia internasional, sarana pelestarian dan pengembangan nilai budaya bangsa, dan berkembangnya film berbasis budaya bangsa yang hidup dan berkelanjutan (Pasal 3 UU No. 8 Tahun 1992 tentang Perfilman). Pada praktiknya peran dan tujuan film saat ini telah melebar ke berbagai aspek kehidupan, mulai dari pendidikan, pengetahuan, sosial dan termasuk juga aspek budaya, sehingga film menjadi semakin populer karena film juga digunakan untuk mengembangkan budaya, serta merepresentasikan sejarah dan budayabudaya lokal suatu daerah atau negara.Indonesia merupakan sebuah negara dan memiliki berbagai macam suku, bahasa dan budaya. Keberagaman dan keberadaan suku, bahasa dan budaya tersebut menjadi kekayaan yang besar dan perlu terus dipelihara dan dikembangkan oleh pemerintah dan dinas-dinas terkait . Keberadaan potensi dan fungsi audiovisual dalam sebuah film menjadikan sebuah tempat mengenai informasi budaya, salah satuyang dapat dicermati yaitu pada keberadaan film-film Indonesia yang terus bermunculan. Penelitian terhadap sebuah film sangat penting dilakukan guna mengetahui adanya keterkaitan sebuah karya film dengan kenyataan yang ada dalam masyarakat, untuk mengetahui nilai-nilai yang terkandung pada sebuahkarya pada dasarnya mencerminkan keadaan sosial dan budaya yang memberikan pengaruh besar terhadap masyarakat. Salah satu film yang memiliki latar 
belakang budaya tersebut adalah sebuah film yang disutradari oleh Benni Setiawan yaitu film Toba Dreams.

\section{I.I. Toba Dreams}

Film ini berlatar belakang tentang kisah cinta yang terlalu mencintai.Cinta yang kadang tersesat dalam menemukan kebenaran.Seperti Sersan Mayor Tebe yang mendidik anak-anaknya layaknya pasukan tempur karena cintanya yang luar biasa kepada mereka.Maka ketika Ronggur, anak sulungnya menjadi pemberontak dalam keluarga, terjadilah konflik mendalam antara ayah dan anak.Ronggur yang sesungguhnya mewarisi tabiat keras ayahnya menemukan cinta dalam diri Andini, seorang wanita Jawa yg berbeda agama.Film ini adalah tentang mimpi Sersan Mayor Tebe yang ingin hidup dengan tenang dan damai mengandalkan uang pensiunan tentara dan memilih pulang untuk membangun kampung halamannya. Tapi Ronggur menolak, ia ingin membuktikan bahwa selama ini ayahnya salah memilih jalan hidup. Dengan penuh siasat Ronggur menjelma menjadi pentolan mafia narkoba dan merebut Andini dari orangtuanya yang tak merestui hubungan mereka.

Film ini berawal dari dipurna bhaktikan Sersan Mayor Tebe (Mathias Muchus), yang telah mengabdi pada negara dengan baik dan tanpa cela. Pulang ke rumah minta kepada anaknya agar sertifikat di pigura, lalu mengajak keluarganya keluar dari rumah dinas di Jakarta dan kembali ke kampungnya di Toba Samosir, Sumatera Utara. Meski ditentang oleh anak pertamanya Ronggur (Vino G. Bastian), Tebe tetap pada pendiriannya.Ronggur keberatan pindah, karena sudah memiliki pacar cantik di Jakarta, padahal dia belum bekerja dan hanya berantem saja.Karena kepandaian membujuk ibunya, akhirnya keluarga Tebe pindah ke Sumatera Utara.Tinggal di rumah bolon tanpa kamar, dan mandi di danau. Tebe gemar mengatur anak-anaknya, seperti saat dia mengatur anak buahnya di medan tempur. Ronggur dimintanya ke sekolah pendeta, anak ke dua Sumurung (Haykal Kamil) diminta masuk ke Akademi Militer, sedangkan si bungsu Taruli, diminta masuk SMA terbaik di Soposurung. Sifat ke tiga anak Tebe berbeda-beda, satu-satunya yang paling memahami Tebe hanya sang isteri. Ronggur paling keras kepala sama dengan sifat Tebe dan melawan setiap usulan Tebe. Sumurung lebih santun, meski melawan namun dengan cara halus, misal saat Sumurung menyatakan tidak layak masuk Akademi Militer dan ingin masuk ke Sekolah Pendeta. Sementara si bungsu sangat penurut, meski dibelakang sebenarnya memberontak.

Ronggur galau dan sering menghabiskan waktu mabuk-mabukan di lapo tuak, akhirnya memutuskan niat ke Jakarta, untuk menemui pacarnya Andini (Marsha Timothy).Ternyata Andini sudah dijodohkan oleh orang tuanya dengan anak seorang Jenderal.Karena kecewa, Ronggur lalu mencari rumah temannya Tommy (Ramon Y. Tungka), namun sudah disita KPK, karena ayahnya terlibat kasus korupsi.Tommy dengan dua adiknya tinggal di rumah neneknya dan bekerja menjadi sopir taksi.Daripada luntang lantung, Ronggur akhirnya menjadi sopir taksi juga dan berhasil membawa kabur pacarnya tiap pulang dari kampus. Kehidupan Ronggur berubah 180 derajat, ketika ketemu bandar narkoba yang mobilnya mogok dan naik ke dalam taksinya.Karena kagum dengan mental kuat Ronggur, bandar narkoba menawarkan pekerjaan membawa kue. Semula Ronggur menolak, karena tipu daya sang bandar narkoba, akhirnya bersedia bergabung. Meski setelah tahu Ronggur meninggalkan kawanan narkoba tersebut ( Sumber : https://www.kompasiana.com/sutiono/564ec1ec759373e3068bbee3/toba-dreams-drama-manusiaantar-budaya-dan-agama diakses pada tanggal, 21-07-2020). 


\section{I.II. Mise-En-Scene}

Kata mis-en-scene adalah segala hal yang terletak di depan kamera yang akan diambil gambarnya dalam sebuah produksi film. Mise-en-scene sendiri berasal dari bahasa Perancis yang memiliki arti "putting in the scene". Mise-en-scene mempunyai arti yaitu unsur sinematik yang paling mudah kenali dan hampir seluruh gambar yang dilihat dalam film adalah bagian dari unsur ini (Pratista, 2008: 62). Adapun aspek yang terdapat dalam miseen-scene ini adalah sebagai berikut.

\section{Setting (latar)}

Setting adalah seluruh latar bersama segala propertinya. Properti dalam hal ini adlah semua benda yang tidak bergerak seperti perabot, pintu, jendela, kursi, lampu, pohon. Setting yang digunakan dalam sebuah film umumnya dibuat senyata mungkin dengan konteks ceritanya. Setting yang sempurna pada prinsipnya adalah setting yang otentik. Setting juga harus meyakinkan penonton jika film tersebut tampak sungguh-sungguh terjadi pada lokasi waktu dan sesuai konteks (Pratista, 2008: 62).

2. Kostum dan Make up

Kostum atau busana merupakan segala hal yang dikenakan oleh pemain. Menurut Himawan Pratista (2008:71) kostum dalam sebuah film tidak hanya sekedar sebagai penutup tubuh semata, namun juga memiliki beberapa fungsi sesuai dengan konteks naratifnya, yaitu : Penunjuk ruang dan waktu, Penunjuk status sosial, penunjuk kepribadian pelaku cerita, warna kostum sebagai simbol, motif penggerak cerita, Image (citra). Kostum yang digunakan bisa mencerminkan kebudayaan suatu daerah yaitu melalui model, jenis, karakter pakaian itu sendiri, sedangkan tata rias wajah atau biasa disebut dengan make-up dalam sebuah film memiliki dua fungsi yakni untuk menunjukkan usia dan untuk menggambarkan wajah nonmanusia (Pratista, 2008:74)

\section{Pergerakan Pemain}

Karakter merupakan pelaku cerita yang memotivasi naratif dan selalu bergerak dalam melakukan sebuah aksi. Hal yang haus diingat adalah bahwa pelaku cerita dapat memmiliki wujud fisik yang beragam dan tidak selalu beruwujud manusia. Pelaku cerita juga dapat dikelompokkan menjadi beberapa jenis sesuai tuntutan dan fungsinya dalam sebuah film (Pratista, 2008: 80).

\section{Dialog}

Dialog dalam film merupakan ucapan yang diucapkan oleh para pemain secara realistis. Menurut Boggs (1992:54), penggunaan tata bahasa, struktur kalimat, perbendaharaan kata-kata dan terutama dialek-dialek khusus oleh seorang aktor, semuanya mengungkapkan tingkat sosial dan ekonomi, latar belakang pendidikan dan proses mental tokoh tersebut. Penggunaan dialog dalam produksi film lebih menekankan bahasa bicara dan aksen. Bahasa bicara dan aksen dalam sebuah film tergantung pada wilayah dan waktu setting cerita yang mampu meyakinkan penonton bahwa film tersebut sungguh- sungguh terjadi di wilayah tersebut. Bahasa dan aksen juga bisa menentukan karakter pada pemain.

\section{Budaya Lokal}

Analisis dalam film Toba Dreams Sutradara Benni Setiawan dapat dilihat dari konsep kebudayaan yang terdiri dari dua sisi. Pertama konsep kebudayaan yang bersifat materialistis, yang mendefinisikan kebudayaan sebagai sistem hasil adaptasi dilingkungan alam atau sistem untuk mempertahankan kehidupan masyarakat. Kedua, konsep kebudayaan yang bersifat idealistis, yang memandang semua fenomena eksternal sebagai manifestasi suatu sistem internal (Sulasman, 2018: 35). Sependapat dengan seorang ahli sosiologi, Talkot Parsons bersama dengan ahli antropologi A.L. Kroeber pernah menganjurkan untuk membedakan secara tajam wujud kebudayaan sebagai suatu sistem dari ide-ide dan konsep, dari wujud kebudayaan sebagai suatu rangkaian tindakan dan 
aktivitas manusia yang berpola (Kroeber, 1958: 582-583). Sementara menurut Koentjaraningrat mengatakan bahwa wujud kebudayaan itu terdiri dari, wujud kebudayaan sebagai suatu kompleks dari ide-ide, gagasan, nilai-nilai, norma-norma, peraturan dan sebagainya, wujud kebudayaan sebagai suatu kompleks aktivitas serta tindakan berpola dari manusia dalam masyarakat, dan wujud kebudayaan sebagai benda-benda hasil karya manusia (Koentjaraningrat, 1979: 200).

\section{Skema Penlitian}

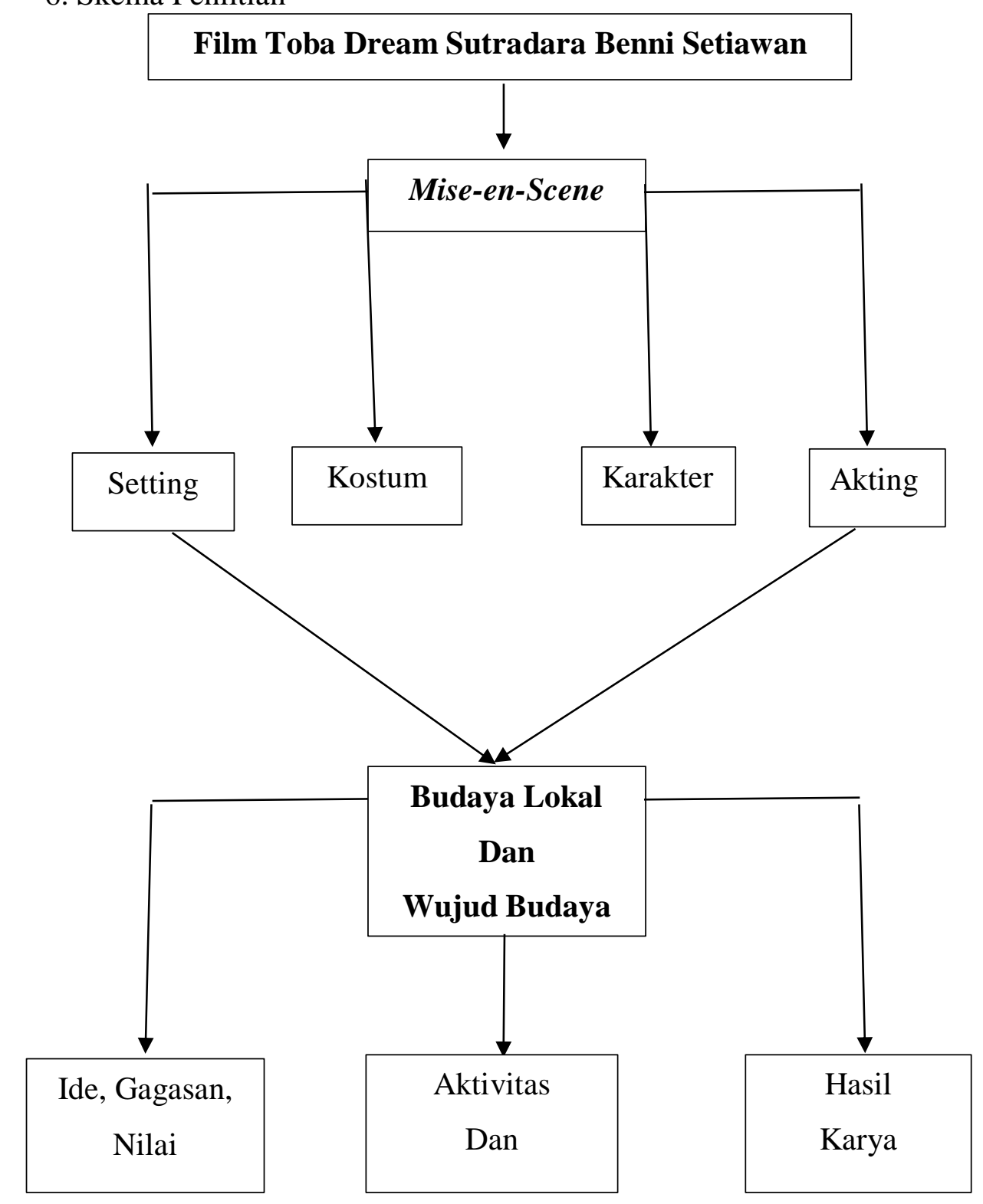

Gambar. 1.

Skema Penelitian

Skema penelitian dimulai ketika film Toba Dreams mulai dianalisis, peneliti menganalisis film Toba Dreams seperti dari mise-en-scene yang kemudian dibagi menjadi settting, kostum, karakter, dan akting. Setelah dari segi mise-en-scene, peneliti masuk kedalam budaya lokal dan wujud budaya lokal, didalam budaya lokal dan budaya lokal dibagi menjadi tiga bagian, pertama ide, gagasan, dan nilai, kemudian yang kedua adalah aktivitas, dan terakhir yang ketiga adalah hasil karya. 


\section{STUDI LITERATUR}

Beberapa referensi penulisan dirujuk oleh peneliti dalam tulisan ini adalah sebagai berikut.

1. Jurnal Shabrina Opelia dengan Judul "Analisis Identitas Budaya Lokal Minangkabau Melalui Mise-En-Scene Dan Dialog Pada Film "Tenggelamnya Kapal Van Der Wijck", Tahun 2018. Jurnal yang ditulis oleh Mahasiswa Institut Seni Indonesia Yogyakarta Program Studi Film dan Televisi Jurusan Televisi Fakultas Seni Media Rekam. Penelitian yang diangkat dalam penelitian ini adalah mengangkat identitas budaya lokal Minangkabau menggunakan mise-en-scene dan dialog pada film tenggelamnya Tenggelamnya Kapal Van Der Wijck. Hasil penelitian ini menunjukkan analisis identitas budaya Minangkabau yang dilihat dari wujud wujud budaya lokal pada film "Tenggelamnya Kapal Van Der Wijck" ditunjukkan melaui aspek mise-en-scene dan dialog. Budaya lokal Minangkabau yang terdapat pada Film "Tenggelamnya Kapal Van Der Wijck" terihat dari setting ruang dan waktu cerita, kostum dan make up yang digunakan oleh pemain, pergerakan akting dan karakter pemian, dan dialog yang diucapkan oleh pemain. Persamaan dalam penelitian ini adalah yaitu membahas identitas budaya lokal namun perbedaannya terletak pada objek film dimana jurnal Shabrina Opelia membahas mengenai adat dan budaya minang pada film "Tenggelamnya Kapal Van Der Wijck". Sedangkan penulis mengungkap adat dan budaya Batak Toba pada film Toba Dreams Sutradara Benni Setiawan.

2. Jurnal Dani Manesah dengan Judul "Aspek Sosial Budaya Pada Film Mutiara dari Toba Sutradara William Attapary”, Tahun 2017. Jurnal yang ditulis oleh dosen Universitas Potensi Utama Program Studi Televisi dan Film Fakultas Seni dan Desain. Penelitian yang diangkat ini adalah mengangkat aspek sosial budaya pada film Mutiara dari Toba Sutradara William Attapary menggunakan Semiotika. Persamaan dalam penelitian ini adalah sama-sama membahas budaya sebagai kajiannya namun perbedaannya peneliti menggunakan mise-en-scene dan dialog dalam pemecahan masalahnya sedangkan penelitian sebelumnya menggunakan semiotika sebagai pemecahan masalahnya.

3. Selanjutnya adalah Jurnal Devy Rianty Anwar dengan judul "Representasi Budaya Bontang Dalam Film 12 Menit Untuk Selamanya", Tahun 2018 Jurnal yang ditulis oleh mahasiswa Universitas Mulawarnam Jurusan Ilmu Komunikasi Fakultas Ilmu Sosial dan Ilmu Politik. Objek yang diteliti dalam penilitian ini adalah Untuk mengetahui bagaimana Film 12 Menit Untuk Selamanya merepresentasikan budaya Bontang. Peneliti menggunakan teori representasi yang dicetuskan oleh Stuart Hall pada tahun 1997.Persamaan dalam penelitian ini adalah sama-sama mengakaji film, namun perbedaannya peneliti meneliti Identitas budaya lokal menggunakan mise en scene dan dialog, sementara peneliti sebelumnya menggunakan teori representasi untuk memecahkan masalah.

\section{PEMBAHASAN}

Film merupakan sebuah karya seni yang dapat menyampaikan dan menyalurkan pesan kepada para penontonnya. Pratista mengatakan film adalah kombinasi antara bahasa suara dan bahasa gambar dan bisa diterima baik oleh penontonnya melalaui pengalaman mental dan budaya yang dimilikinya (Pratista, 2008: 3). Adapun pembahasan terhadap 
Analisis Identitas Budaya Lokal Pada Film Toba Dreams Sutradara Benni Setiawan Melalui Mise-En-Scene dan Dialog dapat dilihat dibawah ini melalui Mise-En-Scene dan Dialog.

\section{A. Mise-En-Scene}

\section{Setting}

Toba Dreams merupakan sebuah film yang disutradarai oleh Benni Setiawan tahun 2015. Dimana lokasi syuting film Toba Dreams dilakukan di seputaran Danau Toba, Balige, Sumatera Utara. Danau Toba merupakan sebuah kawasan objek tempat wisata yang ada di Sumatera Utara. Danau Toba tercatat sebagai danau air tawar kebanggan rakya Indonesia khususnya masyarakat Sumatera Utara. Adapun lokasi syuting film Toba Dreams dapat dilihat pada gambar dibawah ini.

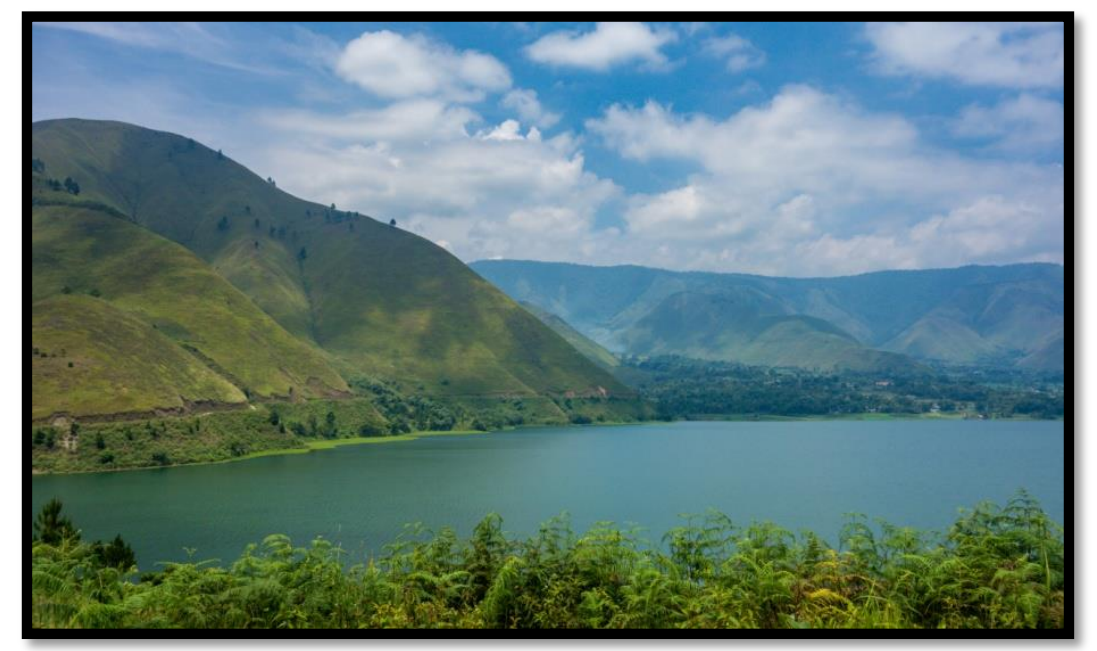

Gambar 1. Lokasi Syuting Film Toba Dreams

Sumber : https://www.youtube.com/watch?v=YaVRzP78wz0

2. Kostum dan Make Up

Ulos merupakan pakaian adat masyarakat Batak Toba terlihat dalam scene pada saat keluarga Sersan mayor Tebe pulang kekampung bersama anak dan istrinya, dimana kedatangan kelaurga Sersan mayor Tebe disambut oleh Ibu dari Sersan mayor Tebe dengan menggunakan baju biasa dan menggunakan penutup kepala atau yang bisa disebut dengan tudung. Pakaian yang dikenakan oleh ibu dari Sersan mayor Tebe yaitu berupa baju biasa dan pentupp kepala. Bagi masyarakat Batak Toba, ulos merupakan kain tenun khas Batak. Sebagai peninggalan leluhur yang hidup di dataran-dataran tinggi pegunugan, Ulos dimaksudkan untuk menjaga tubuh tetap hangat. Secara harfiah Ulos berati selimut yang menghangatkan tubuh, melindungi dari terpaan udara dingin. Dari sinilah lahir uangkapan bahwa, bagi leluhur orang Batak, ada tiga sumber yang memberi kehangatan pada manusia, yakni matahari, api dan Ulos. Bagi masyarakat Batak Toba, ulos penutup kepala dikenal dengan sebutan Sortali. Sortali adalah ikat kepala yang fungsinya seperti mahkota. Biasanya dibuat dari bahan tembaga yang disepuh dengan emas, lalu dibungkus dengan kain merah. Sortali ini digunakan pada pesta-pesta besar baik pada laki-laki dan perempuan. Sama seperti Ulos, penggunaan Sortali tidak sembarangan dan memiliki aturan sendiri. Namun dalam perkembangannya di zaman modern, penutup kepala (tudung) masyarakat Batak Toba kini menggunakan kain atau sarung Saong yang dipakai dalam kesehariannya seperti pergi untuk ke pasar, kebon dan lain-lain. Pada scene berikut merupakan penggunaan saong yang digunakan oleh masyarakat 
Batak Toba dan terdapat pada film Toba Dreams. Adapun penggunaan saong dapat dilihat pada gambar dibawah ini.

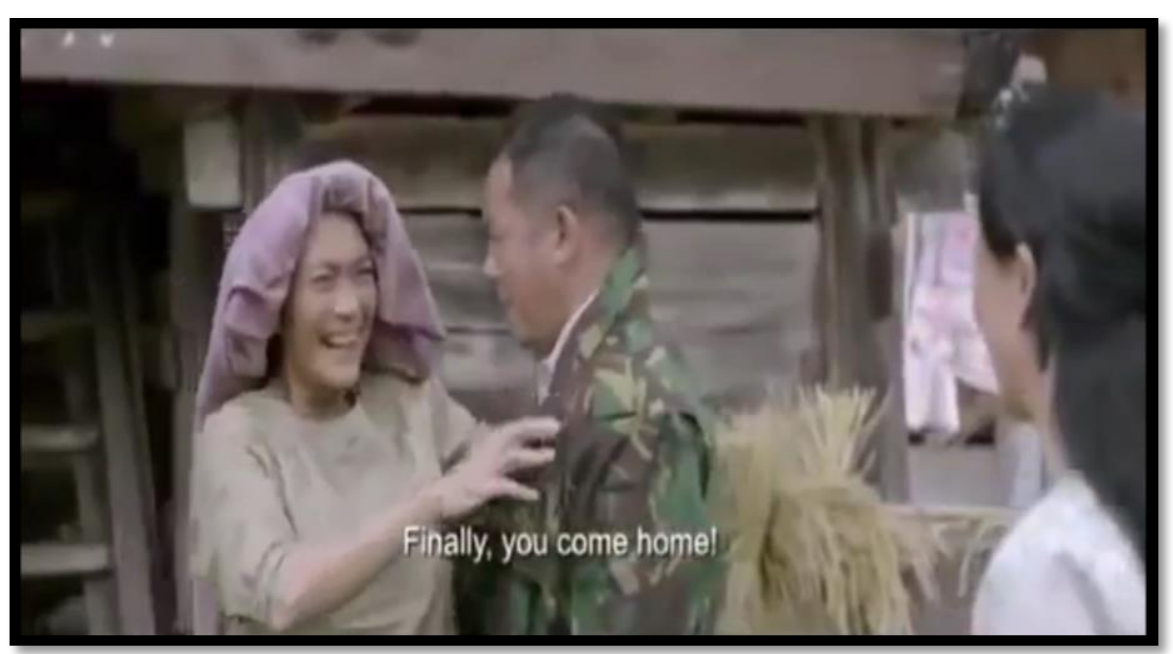

Gambar 2. Penggunaan saong pada film Toba Dreams.

Sumber : https://www.youtube.com/watch?v=YaVRzP78wz0

Dengan tudung kepala menggunakan kain memiliki beberapa fungsi, tuk menjaga dari paparan sinar matahari langsung, untuk penahan saat membawa beban di atas kepala dan juga bisa menutup leher bagian belakang (Sumber https://www.rekamindonesia.id/v/tudung-1444 diakses pada tanggal 19 April 2020 Pukul 16.33 WIB). Make up yang digunakan oleh ibu Sersan Mayor Tebe menunjukkan karakter pada dirinya. Karakter masyarakat Batak Toba yang sederhana, dan bersahaja. Make up yang digunakan ibu Tb. Silalhi yaitu make up yang sederhana dan terlihat natural. Dan adat masih terasa dalam film tersebut, sehingga make up yang digunakan normal dan alami.

3. Pergerakan Pemain.

Pada scene berikut diawali dengan adegan Mathias Muchus yang berperan dengan sangat apik sebagai Sersan Tebe, yang baru saja resmi pensiun dari kesatuannya di TNI Angkatan Darat dan dapat dilihat pada gambar dibawah ini.

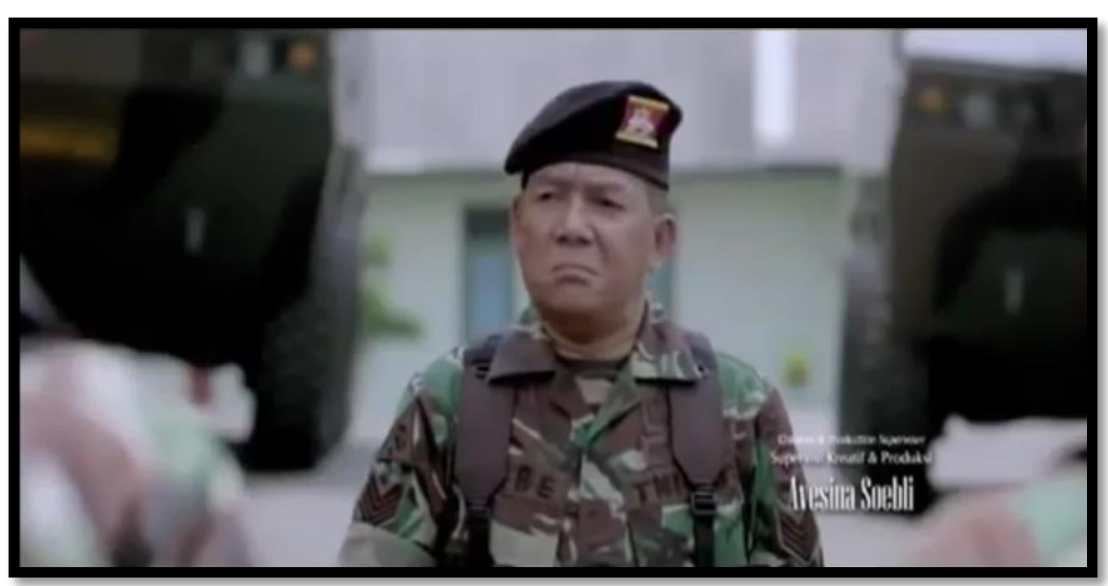

Gambar 3. Sersan Tebe yang resmi pensiun dari kesatuannya Sumber : https://www.youtube.com/watch?v=YaVRzP78wz0 
Sebagai pensiunan tentara, Tebe mendidik anak-anaknya layaknya pasukan tempur karena cintanya yang luar biasa kepada mereka. Maka ketika Ronggur, anak sulungnya menjadi pemberontak dalam keluarga, terjadilah konflik mendalam antara ayah dan anak Tebe yang memiliki tiga anak dan tinggal di rumah dinas alias asrama tentara ini merasa tak akan sanggup lagi meneruskan hidup di Jakarta dengan tingkat ekonomi yang rendah.

4. Dialog

\begin{tabular}{|c|}
\hline Dialog \\
\hline Sersan Tebe \\
"Dengan uang pesiunan bapak yang tidak seberapa ini, rasanya kita sulit untu \\
bisa hidup di Jakarta, belum lagi kita mau kontrak rumah, seperti yang kalian \\
tau, Bapak sudah tidak punya hak lagi atas rumah ini. Jadi, kita semua pindah \\
ke Kampung. Disana kita masih punya sawah dan masih punya kebun
\end{tabular}

"Ini pak,

Mamak

Sersan Tebe

Nah, Sumurung, tolong kau bingkai, piagam tanda kehormatan Bapak ini , hati-hati jangan sampai rusak.

Iya pak,

Sumurung

\section{Ronggur}

Puluahan tahun bapak mengabdi untuk Negara ini, Cuma selembar kertas ini aja pak, balasannya ? dan kita harus diusir dari rumah ini, bapak liat dong keluar sana pak, banyak tetannga kita yang udah pulahan tahun pensiun, tapi masih tetap tinggal disini, padahal mereka masih punya rumah diluar kompleks.

\section{Sersan Tebe}

"Kau samakan bapak dengan mereka. Rumah ini buat prajurit aktif , bukan untuk pensiunan, kalau semua asrama ini dipenuhi dengan pensiunan, sedangkan prajurit aktif tersebar dimana-mana, lalu bagaiman kalau keadaan Negara tidak aman.

\section{Ronggur}

Itu tugas Negara pak, bukan urusan kita. Hari ini masih sok idialis pak?

Sumurung 
Jaga mulut kau bang.

Penggalan diatas merupakan antara Sersan Tebe, Ronggur dan Sumurung. Yang menunjukkan pertentangan Ronggur dan Bapaknya yang tidak setuju dengan keputusan Sersan Tebe untuk mengajak keluarganya pulang kekampung. Percakapan tersebut menggunakan logat masyarakat Batak yang terdengar sedikit kasar dan keras.

B. Wujud Budaya Lokal Masyarakat Batak Toba

1. Wujud kebudayaan sebagai suatu kompleks dari ide-ide, gagasan, nilai-nilai, norma-norma, peraturan.

\begin{tabular}{|c|}
\hline Percakapan \\
\hline Masyarakat \\
"Bah, Horas Pak Tebe \\
Sersan Tebe \\
Mau kemana ini ?
\end{tabular}

Pada penggalan percakapan diatas tokoh Sersan Tebe sudah berada dikampung dan mereka disambut oleh masyarakat sekitar dengan suka cita. Seperti pada gambar dibawah ini.

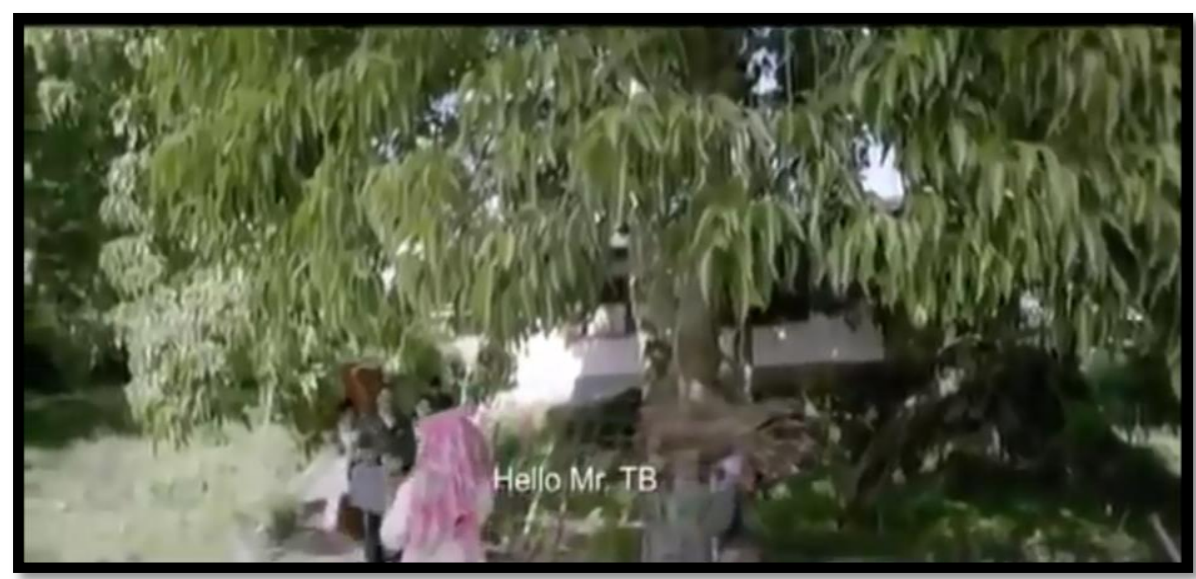

Gambar 4. Sersan Tebe Tiba dikampung

Sumber : https://www.youtube.com/watch?v=YaVRzP78wz0

Berdasarkan sistem masyarakan Batak Toba yang terdapat dalam film Toba Dreams istilah "Horas" digunakan oleh Sersan Tebe yang tiba di Kampung kepada masyarakat. DalaM salam khas Batak. Kata "horas" adalah ungkapan rasa gembira dan syukur dan juga pengharapan atas keselamatan dan berkat dari Tuhan Yang Maha Esa. Horas diucapkan pada saat berjumpa maupun saat akan berpisah. Horas juga digunakan sebagai salam pembuka dan penutup dalam setiap acara Batak ( Sumber https://www.horas.web.id/2013/07/artikata-horas.html, diakses pada tanggal 19 April 2020 Pukul 18.15 WIB).

2. Wujud kebudayaan sebagai suatu kompleks aktivitas serta tindakan berpola dari manusia dalam masyarakat. 
Terdapat sebuah scene yang menggambarkan masyarakat Batak Toba sedang menggarap sawah dan menanam padi disawah. Yang terlihat pada gambar dibwah ini.

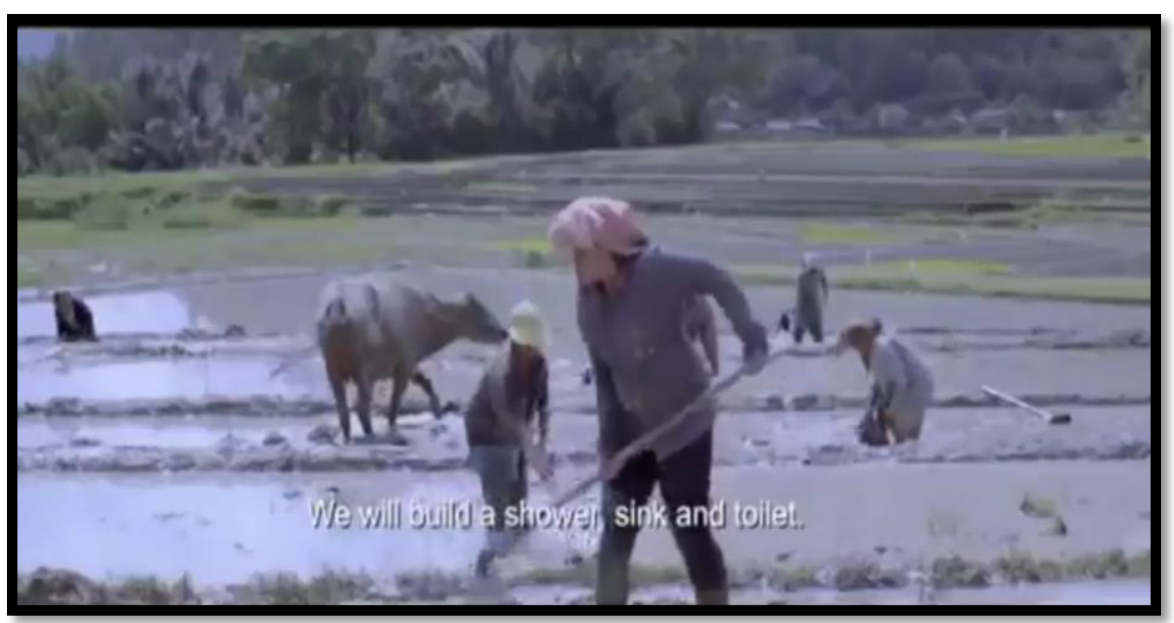

Gambar 5. Masyarakat Batak Toba yang sedang menanam padi

Sumber: http://youtube.com

Masyarakat Batak Toba terutama hidup dari pertanian. Berabad-abad lamanya mereka mengusahakan pertanian sawah dengan perairan terpadu. Maka tidak heran kalau orang Batak Toba berdiam di lembah-lembah dan sekitar Danau Toba sebab di sana ada cukup air untuk persawahan. Kondisi geografis lembah membuat mereka hidup dalam ruang yang terbatas dan terisolasi. Kemudian terdapat salah satu scene yang menunjukkan aktivitas masyarakat yaitu musyawarah atapun mufakat yang dilakukan Sersan Tebe kepada masyarakat lain untuk lebih menjaga kebersihan dan keindahan Danau Toba, yang dapat dilihat pada gambar berikut ini.

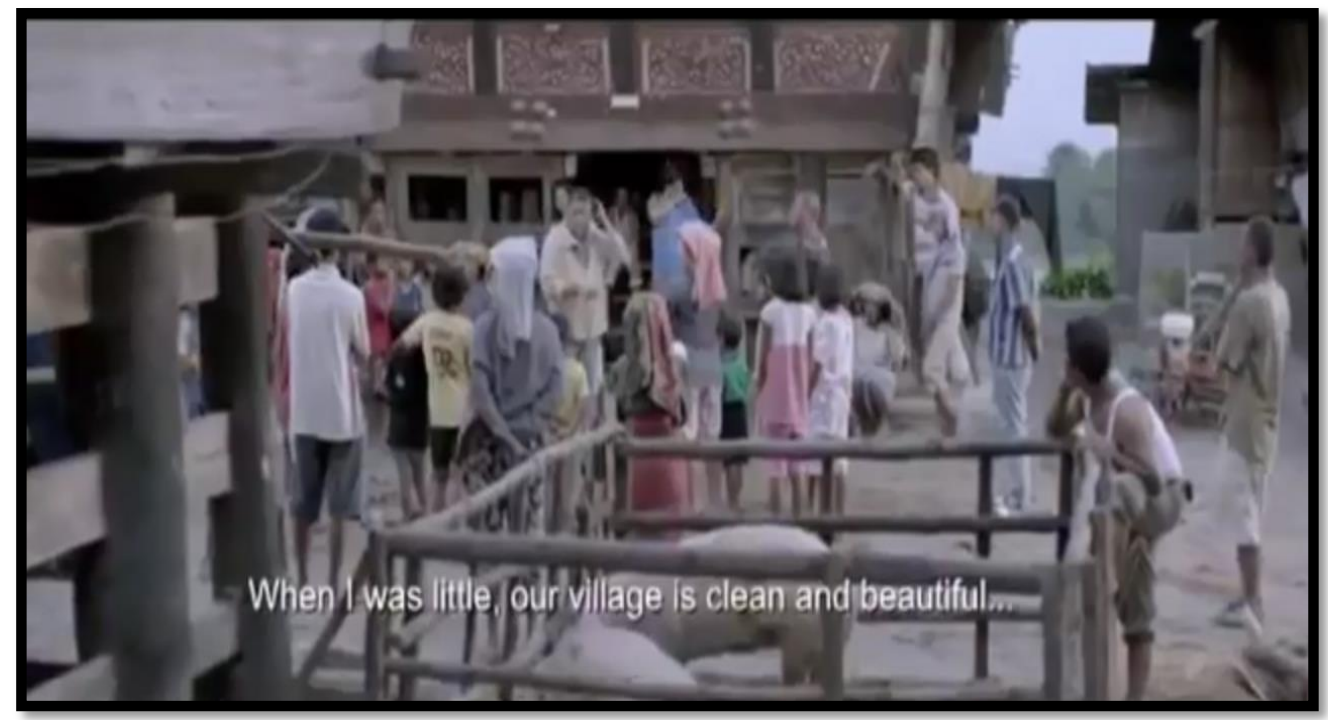

\section{Gambar 6. Sersan Tebe Berkumpul dan Berbicara (Mandok Hata)} Dengan Masyarakat Sekitar

Sumber : https://www.youtube.com/watch?v=YaVRzP78wz0

Secara harafiah, Mandok Hata artinya "berbicara". Dan sebenarnya Mandok Hata ini tidak hanya ada saat tahun baru. Tapi hampir di setiap ulaon (acara perkumpulan) orang Batak seperti pesta pernikahan, pemakaman, kelahiran anak, Natal atau sekadar kumpul 
keluarga, pasti ada Mandok Hata. Isi Mandok Hata bisa berupa pemberian nasihat, penghiburan, curhat dan sebagainya. (Sumber: https://www.kompasiana.com/irmina.gultom/5a48b25bf133445dc213f634/mandok-hatatradisi-khas-tahun-baruan-ala-orang-batak?page=all diakses 22 April 2020).

3. Wujud kebudayaan sebagai benda-benda hasil manusia.

Wujud kebudayaan berupa benda-benda hasil karya manusia sifatnya paling konkret. Wujud kebudayaan ini berupa fisik, dapat dilihat dan didokumentasikan. Wujud kebudayaan ini ditemukan dalam Film Toba Dreams Sutradara Benni Setiawan yaitu : bangunan Rumah Adat Sopo Godang yang terlihat pada setting film dan kostum para pemainnya pada film Toba Dreams. Rumah adat Sopo Godang dapat dilihat pada gambar berikut ini.

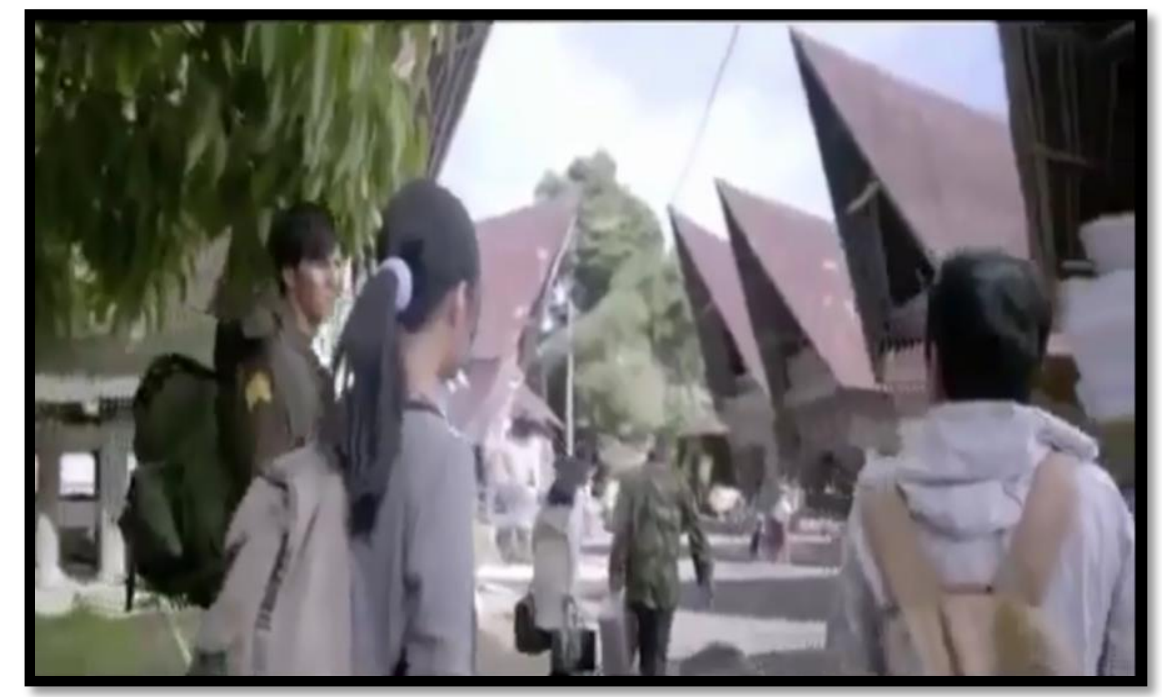

Gambar 7. Rumah Adat Sopo Godang

Sumber: http://youtube.com

\section{PENUTUP}

Berdasarakan hasil pembahasan dan analisis terhadap identitas budaya lokal pada film Toba Dreams Sutradara Benni Setiawan terdapat wujud budaya pada film Toba Dreams seperti Wujud kebudayaan sebagai suatu kompleks dari ide-ide, gagasan, nilai-nilai, normanorma, peraturan yang terdapat pada gambar diatas. Selanjutnya wujud kebudayaan sebagai suatu kompleks aktivitas serta tindakan berpola dari manusia dalam masyarakat yang terdapat pada gambar saat pergi berladang dan menanam padi disawah. Kemudian selanjutnya terdapat wujud kebudayan sebagai benda-benda hasil manusia yang terdapat pada gambar tersebut. 


\section{DAFTAR PUSTAKA}

[1] Anwar, Rianty Devi. 2018." Representasi Budaya Bontang Dalam Film 12 Menit Untuk Selamanya". eJournal Ilmu Komunikasi Universitas Mulawarman. Vol.6, No.1.

[2] Boggs.M, Joseph. Cara Menilai Sebuah Film. Terjemahan Asrul Sani. Jakarta : Yayasan Citra. 1992.

[3] Koentjaraningrat. 1979 Pengantar Ilmu Antropologi. Jakarta. Aksara Baru.

[4] Manesah, Dani.2018. “Aspek Sosial Budaya Pada Film Mutiara Dari Toba Sutradara William Attapary”. Jurnal Proporsi Universitas Potensi Utama. Vol. 2 No.2.

[5] Mascelli, Joseph V. The Five C'S Of Cinematography (Lima Jurus Sinemotografi), terj. Jakarta: Fakultas Film dan Televisi IKJ. 2010.

[6] Ophelia, Shabrina. 2018. Analisis Identitas Budaya Lokal Minangkabau Melalui Miseen-scene dan Dialog Pada Film “Tenggelamnya Kapal Van Der Wijk”. Skripsi Jurusan Televisi Institut Seni Indonesia Yogyakarta.

[7] Pratista Himawan. 2008.Memahami Film. Yogyakarta: Homerian Pustaka.

[8] Sulasman dan Gumilar Setia.2018. Teori-Teori Kebudayaan Dari Teori Hingga Aplikasi.Bandung: CV Pustaka Setia.

\section{Webtografi.}

http://pustaka-makalah.blogspot.com/2011/03/kebudayaan-dalam-kehidupanmasyarakat.html

http://digilib.uinsby.ac.id/13666/5/Bab\%202.pdf

https://docplayer.info/52080722-Islam-and-trans-cultural-in-education.html

http://digilib.isi.ac.id/4252/6/JURNAL\%201110586032.pdf

https://docplayer.info/144717594-Analisis-identitas-budaya-lokal-minangkabau-melaluimise-en-scene-dan-dialog-pada-film-tenggelamnya-kapal-van-der-wijck.html

https://books.google.com/books?id=aZHKmu8wCVcC

https://suka-suka.web.id/cara-menulis-kutipan-yang-benar/

http://febriyantirf.blogspot.com/2017/12/

https://www.rekamindonesia.id/v/tudung-1444

http://visitsamosir.com/adat-dan-budaya-batak/ 